\title{
Stress and EEG
}

\author{
Ssang-Hee Seo and Jung-Tae Lee \\ Department of Computer Science \& Engineering, Pusan National University \\ 30, Jangjeon-Dong, Geumjeong-Gu Busan, \\ Korea
}

\section{Introduction}

Many people suffer from stress in their everyday life. While there is a close relationship between stress and mental health, psychological stress (and associated emotions such as anger, anxiety, and depression), can also have effects on physical health. Indeed, chronic psychological stress can change the responsiveness of central-peripheral regulatory systems (Fuchs \& Fluegee 1995; Fuchs, Uno, \& Fluegge 1995), potentially rendering them less efficient or adaptive in terms of supporting health. Conditions such as chronic stress, depression, and anxiety have been found to be associated with abnormal autonomic nervous system (ANS) functioning (Cohen et al., 2000; Hughes \& Stoney 2000). Accordingly, stress is one of the major factors contributing to chronic disorders (Decker et al., 1996; Lawrence \& Kim 2000).

Stress also influences the desire to work, performance at work, and one's general attitude toward life (NIOSH, 1999). Within the industry sector, higher stress levels and stress-related disease lead to decrease in company performance and increase in medical expenses (Cooper, 1996; Manning, et al., 1996). In 2008 in Korea, there were 1,967 deaths associated with occupational cases. Almost half of these deaths (974, or $49.5 \%$ ) could be ascribed to heart or brain blood vessel disease (Ministry of Labor, 2008). This is not surprising given that stress is implicated in $75 \%$ of all heart and brain blood vessel diseases (Belkic, et al., 2004). It is thus apparent that stress can increase social and economic losses and decrease a country's competitiveness (Driskell \& Salas, 1996). Therefore, precautionary measures to reduce stress and adequate management of this condition are essential for both individual health and the welfare of society at a broader level.

This chapter reports on relationships among psychological stress, the EEG (Electroencephalogram), ECG, and salivary cortisol in people suffering from chronic stress. We hypothesized that chronic stress will have negative effects on the central-ANS and physiological responsiveness. There are many bio-signal channels by which stress can be potentially quantified, including ECG, EEG, and the skin conductance response (SCR) (Kohlish \& Schaefer 1996; Gevins et al., 1998). Even so, determining the stress level of any given individual can be difficult. Related to this is debate concerning the extent to which the EEG can be used to reliably measure stress. However, this chapter presents data showing that there are significant correlations between EEG measures and other indices of stress, including the ECG and salivary cortisol. Also, it revealed relationships between high beta

Source: Convergence and Hybrid Information Technologies, Book edited by: Marius Crisan, ISBN 978-953-307-068-1, pp. 426, March 2010, INTECH, Croatia, downloaded from SCIYO.COM 
frequency EEG activity and each of HRV, measured as the standard deviation of all normal RR intervals (SDNN) and salivary cortisol during several different conditions. Our results suggest that inter-individual differences in stress can be reliably assessed by EEG.

\section{The stress response}

The human nervous system is very complex and contains two major divisions: central and peripheral. The peripheral nervous system includes the ANS, which has a particular association with negative psychological states such as stress, anxiety, and depression.

The ANS performs and regulates automatic bodily functions associated with breathing, heart rate, digestion, and the hormonal system. The ANS itself has two parts: sympathetic and parasympathetic. The sympathetic and parasympathetic nervous systems initiate the stress and relaxation response, respectively.

There is normally a balance maintained between the activities of the sympathetic and parasympathetic nervous systems. Chronic stress can disturb this balance and thereby cause stress-related health problems to arise.

When one is exposed to a physical or psychological stressor, the brain initiates a stress response, from which a series of chemical reactions ensue. The stress response is a healthy defense mechanism and involves the release of hormones that have numerous biochemical and physiological effects. However, the continued release of these hormones under conditions of chronic stress can have detrimental effects on health.

Indeed, the hormonal response associated with long-lasting stress increases the risk of many diseases, including heart disease, stroke, and angina. Stress hormones can weaken the immune system and thus promote vulnerability to infection. Stress hormones also trigger increases in blood pressure, heart rate, and respiration and raise the risk of stroke, heart attack, and kidney diseases (Noback et al., 1986).

Cognitive and physiological processes of the central nervous system (CNS) associated with stress are known to affect most organs of the human body.

The stress response involves activation of regulatory centers in the CNS that stimulate both the hypothalamic-pituitary-adrenal (HPA) axis and ANS.

The HPA axis is one of the major systems involved in the stress response. It facilitates adaptations to changes in the internal or external conditions of the body. The stress response involves central and peripheral changes that are coordinated by the CNS. The release of glucocorticoids (GCs) such as cortisol is controlled by the paraventricular nucleus of the hypothalamus, in which parvocellular neurons synthesize and release corticotrophinreleasing hormone $(\mathrm{CRH})$ as a response to stress. These neurons also secrete other hormones, including arginine vasopressin. The combined actions of arginine vasopressin and CRH activate the HPA axis. The release of CRH into the pituitary portal system induces the pituitary to release adrenocorticotropic hormone (ACTH), which in turn induces the release of GCs from the adrenal cortex. GCs exert negative feedback on the hypothalamus and pituitary gland that serves to terminate the stress response when no longer required, thereby preventing excessive responses. GCs are involved in many aspects of the stress response; they facilitate adaptation of the body to changing conditions by regulating energy stores, inhibiting nonessential physiological activity, and promoting behavioral responses to stimuli perceived as stressful (Johnson et al., 1992; Bao et al., 2008). 


\section{Assessing levels of stress}

\subsection{Psychological assessment}

The stress response can be measured and evaluated in terms of perceptual, behavioral, and physical responses. The evaluation of perceptual responses to a stressor involves subjective estimations and perceptions. Indeed, self-report questionnaires are one of the most common instruments used to measure an individual's level of stress (Cohen et al., 1997). Numerous questionnaires have been used in clinical practice and psychiatric research to evaluate stress, including the Perceived Stress Scale (PSS) (Cohen et al., 1983), the Life Events and Coping Inventory (LECI) (Lewis, 1988), and the Stress Response Inventory (SRI) (Koh et al., 2001). The PSS measures the degree to which situations are considered stressful, doing so by addressing events experienced in the preceding month. It was designed to quantify how unpredictable, uncontrollable, and overloaded adults find their lives. The LECI is composed of 125 questions that assess the extent to which children experience stress in association with life events. The SRI is designed for adults, but it differs from the PSS in assessing the mental and physical symptoms associated with psychological stress; it consists of 39 items and produces scores for seven factors: tension, aggression, somatization, anger, depression, fatigue, and frustration.

\subsection{Physical assessment}

The physical response to stress has two components: these are a physiological response indicative of central-autonomic activity and a biochemical response involving changes in the endocrine and immune systems (Cohen, Kessler \& Gordon 1997).

\subsubsection{Biochemical response}

Stress induces changes in autonomic function and the secretion of hormones that include cortisol, corticosterone, and adrenal catecholamines (Van der Kar \& Blair 1999).

The presence of stress hormones such as adrenaline, noradrenaline, and cortisol can be considered indicative of a stress response. Some studies have reported that repeated exposure to intense stress increases the secretion of cortisol (Schulz et al., 1998; Evans et al., 2001). Cortisol levels can be measured in numerous bodily fluids, including serum, urine, and saliva. There is a daily cycle in cortisol levels, which are normally high in the morning and low at night (Stone et al., 2001). However, repeated exposure to stress decreases the ability to regulate cortisol levels, leading to an elevated level that remains high at night. In such case, the levels may become abnormally low and show very little variation (Dallman, 1993; Pruessner et al., 1999). It has been shown that there are relationships between salivary cortisol levels and physiological variables used to assess stress, including HRV, skin temperature, blood pressure (BP), heart rate (HR), and galvanic skin response (GSR). Accordingly, salivary cortisol is routinely used as a biomarker of psychological stress and associated mental or physical diseases. Exposure to long-lasting stressors often results in elevated cortisol levels (Bigert, Bluhm, \& Theorell 2005). Indeed, salivary cortisol is generally considered to be a reliable measure of HPA adaptation to stress (Park, \& Kim 2007).

\subsubsection{HRV (Heart rate variability)}

Stress induces a change in autonomic functioning (Van der Kar \& Blair 1999). Blood pressure and heart rate increase during stress, reflecting a predominance of sympathetic 
nervous system activity (Ritvanen et al., 2005). HRV is the beat-to-beat variation in heart rate, and it has recently been used as a biomarker of ANS activity associated with mental stress (Zhong et al. 2005). Time domain analysis of HRV involves quantifying the mean or standard deviation of RR intervals. Frequency domain analysis involves calculating the power of the respiratory-dependent high frequency and low frequency components of HRV. While high frequency power is mediated by vagal activity (Hayano et al., 1991), it has been suggested that low frequency power primarily reflects sympathetic modulation (Pomeranz et al., 1985; Malliani et al., 1991). Many studies have investigated abnormalities in ANS functioning associated with stress, with HRV as one of the measures shown to be affected (Salahuddin et al., 2007). Mental stress is reported to evoke a decrease in the high frequency component and an increase in the low frequency component of HRV (Bernardi et al., 2000). Job stress has been shown to induce excessive levels of sympathoadrenal activation, leading to increases in blood pressure and heart rate, the secretion of catecholamines, and the release of lipids and glucose into the bloodstream (Theorel et al. 1993). Abnormalities of ANS functioning (Horsten et al. 1999) that include decreased HRV are associated with mental stress in laboratory experiments (Myrtek et al. 1996; Sloan et al. 1994). Moreover, lower than normal HRV has been found in subjects with depression, high levels of hostility, and anxiety. Low HRV may reflect an inability to generate variable and complex physiological responses, rendering an individual physiologically rigid and vulnerable (Horsten et al. 1999). Sustained autonomic activation can result in arrhythmia or sudden heart attack because of an increase in sympathetic and decrease in parasympathetic activity.

\subsubsection{EEG}

In healthy people not experiencing stress, there is a balance between the sympathetic and parasympathetic arms of the ANS and flexibility in how these respond. Exposure to threatening situations induces a fight-or-flight response whereby emotional and vigilance systems are activated. Although most current day stress arises from psychosocial factors that are not life threatening, the fight-or-flight response may still be generated, for example, during tests or when called upon to give an impromptu speech (Johannes et al 2007). Studies into brain activity patterns under stressful conditions have focused on stress generated by words, examinations, noise, and mental tasks (Matsunami et al., 2001; Lewis et al., 2007; Tucker 1981; Davidson et al., 1979; Seo et al., 2008a; Seo et al., 2009).

A major aspect of neurophysiological research into emotion concerns hemispheric specialization. While the left hemisphere appears to be more involved in the processing of positive emotions and approach-related behaviors, the right hemisphere is more involved in the processing of negative emotions and withdrawal behaviors (Coan \& Allen, 2004; Davidson, 2003). These differences are represented by a model of emotional processing in which the frontal cortex plays a key role. Evidence supporting this model has been obtained from studies concerning asymmetry in prefrontal EEG alpha activity. Positive moods or reactions have been shown to be associated with relatively greater left prefrontal activity (LFA) and negative moods or reactions with relatively greater right prefrontal activity (RFA) (Davidson, Jackson \& Kalin, 2000).

The results of recent neuroimaging studies suggest that negative affect typically elicits activation in the right prefrontal cortex, amygdala, and insula, and the left prefrontal cortex is associated with positive emotions (Davidson; 1992). The right prefrontal cortex may be critically involved in the response to stress, since it is a fundamental component of both the 
emotional and vigilance networks. Some studies suggest that high levels of right-sided prefrontal activation are associated with a negative affective style and weakened immune system. For example, Davidson has reported that differences in prefrontal activity asymmetry reflect individual differences in affective styles (Bierhaus et al., 2003; Epel et al., 2004). Importantly, the prefrontal cortex may mediate the extent to which psychosocial stress affects mental and physical health (Segerstrom \& Miller 2004; Cohen et al., 1993).

There appear to be differences in how activity of the left and right cortical hemispheres affects ANS functioning. Moreover, the extent of this asymmetry has been suggested to vary under conditions of chronic stress (Papousek, 2002). Related effects are reported for stressrelated emotions, with preferential right hemispheric activation in the frontopolar region shown to be associated with electrodermal activity (EDA) in anxious subjects (Papousek \& Schulter, 2001).

\section{Neurofeedback}

The side effects and inconvenience associated with long term use of medications has facilitated an interest in alternative therapies and self-regulation for maintaining health.

Alternative therapies such as yoga, meditation, and Ki Gong are widely used to manage stress. These therapies induce relaxation or decrease psychophysiological arousal by reducing the activities of the sympathetic nervous system. Another therapeutic approach involves biofeedback, in which ANS variables such as heart rate, blood pressure, skin tension, and temperature are regulated. Biofeedback has been applied to mental diseases such as anxiety and depression and to psychosomatic diseases such as migraine, tension headache, and hyperpiesia (Sadock B.J. \& Sadock V.A. 2004). Neurofeedback is biofeedback using brain waves and has specific applications for brain diseases and associated symptoms (Ahn, 2006; Park, 2006). There have been many recent studies concerning the utility of neurofeedback within clinical medicine. Conditions for which neurofeedback has been most intensively used include alcoholism, epilepsy, ADHD, brain injury, and mood disorders (Peniston E.G., 1999; Mann C.A., 1992; Byers A.P., 1995; Baehr E., 2001). In a more general sense, neurofeedback has been demonstrated to improve concentration, memory, and musical performance (Gruzelier J, 2005).

Subjects undergoing neurofeedback training attempt to regulate their brain waves, wherein special signals are presented to the subject in a suitable form. Via operant conditioning, this feedback facilitates a subject's ability to adopt a desired brain wave state. Neurofeedback training focuses upon two components of the EEG spectrum: synchronized beta waves and alpha waves. Alpha waves reflect a calm, open, and balanced psychological state with a decrease in alpha wave activity during stress. Alpha wave training attempts to alleviate stress by inducing a state of relaxation. This involves removing or reducing habitual tendencies to respond to stressful situations with tension and anxiety.

Beta waves are associated with concentration, thought, and listening. Synchronized brain waves reflect attention or awareness or consciousness in the absence of motor activity. Synchronization at low frequencies (delta and theta) reflects awareness on an unconscious level. Conversely, synchronization of higher frequency alpha and beta waves reflects a state of conscious awareness. Beta training is reported to increase focus, concentration, energy levels, and mental clarity (Paul, 2008). Alpha and beta training supplement one another and can be used in combination to manage stress. Neurofeedback is a noninvasive technique potentially effective in reducing stress. However, there may be a particular benefit to be had 
in combining neurofeedback with medications that by themselves have a limited role in managing stress.

\section{Experimental methods}

\subsection{Participants}

The participants were 33 healthy, right-handed volunteers (9 females and 24 males) aged 30-40 years old. All participants had normal hearing, and none had a neurological disorder. Informed written consent was provided by all participants before completing questionnaires or undergoing psychophysiological assessment.

\subsection{SRI(Stress Response Inventory) and SAM(Self Assessment Manikin)}

Stress was assessed with the SRI, which participants completed prior to physiological measurements being obtained.

The SAM (Fig. 1) has been used widely to assess the emotional response of subjects to experimental stimuli. In being pictorial it can be used with people from a diverse range of backgrounds. The SAM quantifies pleasant and unpleasant emotions on a nine-point scale (Margaret et al. 1994).

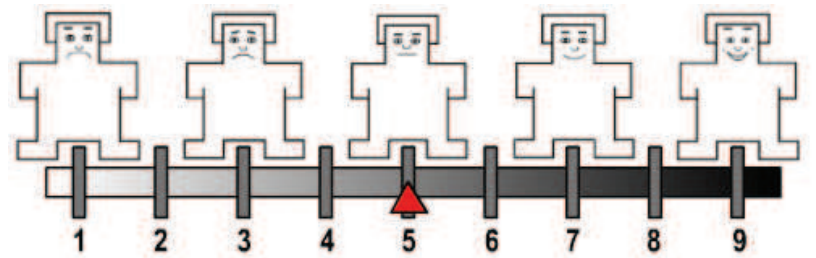

Fig. 1. SAM Valence (negative-positive)

\subsection{Procedures}

Visual stimuli from the International Affective Picture System (IAPS) were used to evoke emotional responses (Lang, Bradley \& Cuthbert 1995). The stimuli were presented as a set of pleasant images and a set of unpleasant images. Each set lasted for $5 \mathrm{~min}$, with individual images presented for $15 \mathrm{~s}$. Participants made a rating with the SAM after each image set. Salivary cortisol was collected after the SRI had been completed, following which participants underwent the sequence of procedures shown in Figure 2: eyes-closed, eyesopen, pleasant images, SAM, rest, unpleasant images, and SAM. EEG and ECG recordings were obtained throughout the experiment. A 5-min portion of the ECG recording was used for short-term HRV analysis.

\subsection{Cortisol}

Cortisol levels quantify the endocrine response to stress. The collection of blood samples for measuring cortisol levels can be associated with greater inter-individual differences than when saliva samples are used (Park \& Kim 2007). Saliva was obtained from our participants between noon and $3 \mathrm{pm}$. Cortisol levels were determined using a Solid-Phase Radioimmunoassay (RIA) Coat-A-Count Cortisol kit (Siemens, USA), as per the manufacturer's instructions, and a Gamma counter (Packard, USA). 


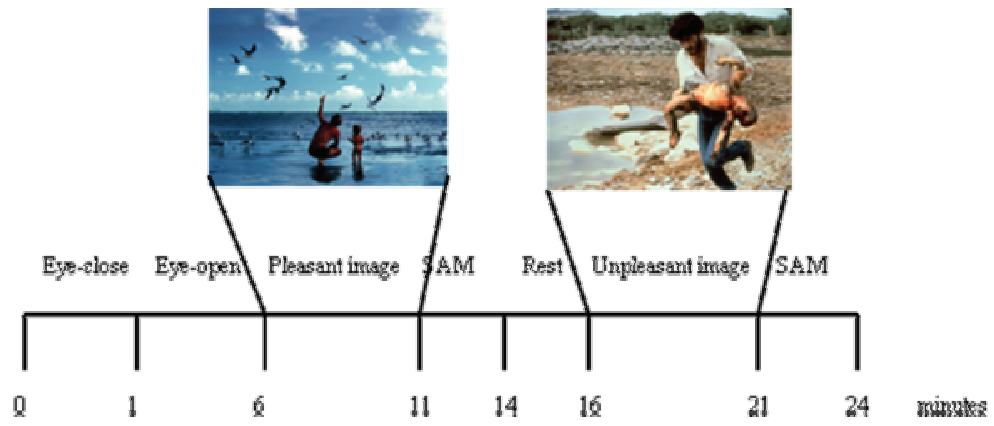

Fig. 2. Experimental sequence

\subsection{ECG recording and analysis}

The ECG was monitored continuously with a noninvasive system developed by us previously. Limb leads II and III were used, and the sampling rate was $512 \mathrm{~Hz}$. HRV analysis requires accurate detection of the QRS complex. However, this can be difficult because ECG signals are easily corrupted by noise generated by muscular contraction or electrical power lines, and by a drift from baseline associated with respiration or motion artifacts. In addressing this issue, we used a novel QRS detection algorithm based on multiscale mathematical morphology $(3 \mathrm{M})$. This was designed to specifically identify $\mathrm{R}$ waves, and with which successive R-R interval series could be reliably determined.

\subsection{EEG recording and analysis}

The EEG was recorded in each of the four conditions designed to induce different levels of stress: eyes-closed, eyes-open, pleasant images, and unpleasant images. Unpleasant and pleasant images were presented to evoke negative and positive emotions, respectively. Participants rested with their eyes closed for $1 \mathrm{~min}$ and with their eyes open for $5 \mathrm{~min}$.

The EEG was recorded with $\mathrm{Ag}-\mathrm{AgCl}$ disc electrodes from four Modified Combinatiorial Nomenclature (MCN) system sites: FC5, FC6, O1, and O2. These were specifically chosen to facilitate the detection of stress, anxiety, and dysphoria, as reflected by beta activity. The reference and ground sites were $\mathrm{Cz}$ and Iz, respectively. A QEEG-4 (LXE1104-RS232, LAXTHA Inc.) device obtained recordings at a sampling rate of $256 \mathrm{~Hz}$. The resolution of the A/D converter was 12 bits, and electrode impedance was maintained as less than $5 \mathrm{k} \Omega$. EEG data was analyzed with Complexity v2.8 software (LAXTHA Inc.). Recordings were band-pass FFT filtered $(4-30 \mathrm{~Hz})$, to eliminate any influence of artifacts in the theta $(4-8 \mathrm{~Hz})$, alpha $(8-13 \mathrm{~Hz})$, and beta $(13-30 \mathrm{~Hz})$ ranges. Ocular artifacts were removed using a PCAbased procedure in Complexity v2.8.

\subsection{Statistical analysis}

Pearson's correlation was used to determine the strength of relationships among EEG, ECG (SDNN), salivary cortisol, and SRI data. Stress levels groupings of stress, non-stress and general were made with k-means cluster analysis of SDNN and cortisol data. Differences in SDNN and cortisol between these groups were examined with ANOVA. All statistical analyses were performed using SPSS v12.0, and considered to be significant at the level of $p$ $<0.05$. 


\section{Results}

\subsection{Relationships among EEG, ECG, salivary cortisol, and SRI data}

Salivary cortisol was negatively correlated with SDNN $(r=-0.498, p=0.07)$. However, there was no significant relationship between SDNN and SRI, or between cortisol and SRI. In general, the high stress group showed decreased HRV features compared to the low stress group under chronic stress (Kim, Seo \& Salahuddin 2008). Long lasting stress can produce elevated cortisol levels and restrict their typical overnight reduction (Bigert, Bluhm, Theorell 2005).

\subsection{EEG and ECG}

The relationship between SDNN and relative high beta power for each of the four EEG sites in the eyes-closed condition is shown in Table 1. There was a significant negative correlation between SDNN and relative high beta power at both the anterior temporal sites in this condition. Significant correlations were not found in any of the other conditions or at either of the occipital sites.

\begin{tabular}{|c|c|c|}
\hline \multirow{2}{*}{ Recording site } & \multicolumn{2}{|c|}{} \\
\cline { 2 - 3 } & $\mathbf{r}$ & $\mathbf{p}$ \\
\hline FC5 & -0.428 & 0.013 \\
\hline FC6 & -0.346 & 0.049 \\
\hline O1 & 0.052 & 0.772 \\
\hline O2 & 0.070 & 0.697 \\
\hline
\end{tabular}

Table 1. Relationships between SDNN and high beta activity in the eyes-closed condition Table 2 shows the results of the k-means cluster analysis by which stress level groupings based on SDNN data were made.

\begin{tabular}{|c|c|c|c|c|c|}
\hline \multirow{2}{*}{} & \multicolumn{3}{|c|}{ Cluster center } & \multicolumn{2}{c|}{ ANOVA } \\
\cline { 2 - 6 } & $\begin{array}{c}\text { Stress } \\
(\mathbf{N}=\mathbf{1 3})\end{array}$ & $\begin{array}{c}\text { Non-Stress } \\
\mathbf{( N = 9 )}\end{array}$ & $\begin{array}{c}\text { General } \\
(\mathbf{N}=\mathbf{1 1})\end{array}$ & $\mathbf{F}$ & $\mathbf{p}$ \\
\hline SDNN & 24.64 & 50.77 & 36.75 & 71.077 & 0.000 \\
\hline
\end{tabular}

Table 2. K-means cluster analysis of SDNN data

The mean high beta power at the anterior temporal sites of each SDNN group is shown in Figure 3. There was a significant difference in high beta activity across the groups at FC5 (F $=4.271, \mathrm{p}=0.023)$ but not at FC6 $(\mathrm{F}=2.262, \mathrm{p}=0.122)$. The stress group (with relatively low SDNN) had the highest level of beta activity.

\subsection{Relationships between salivary cortisol and EEG data}

The relationship between salivary cortisol level and relative high beta power at each of the four EEG sites in the eyes-closed condition is summarized in Table 4. In this condition, there was a significant positive correlation between the cortisol level and relative high beta power at both the anterior temporal sites, and a tendency toward a similar relationship at one of the occipital sites (O2). Significant relationships were not found in any of the other conditions. 


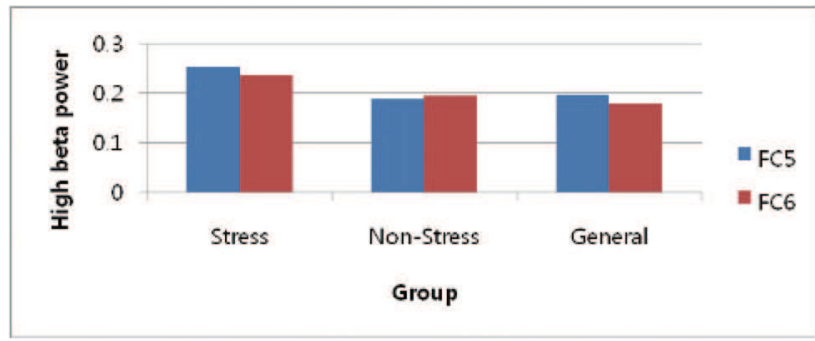

Fig. 3. Relative high beta power in each of the three SDNN-based stress level groups

\begin{tabular}{|c|c|c|}
\hline \multirow{2}{*}{ Recording site } & \multicolumn{2}{|c|}{$\mathbf{p}$} \\
\cline { 2 - 3 } & $\mathbf{r}$ & 0.008 \\
\hline FC5 & 0.454 & 0.011 \\
\hline FC6 & 0.439 & 0.165 \\
\hline O1 & 0.247 & 0.057 \\
\hline O2 & 0.334 & \\
\hline
\end{tabular}

Table 3. Relationships between cortisol and high beta activity in the eyes-closed condition

Table 4 shows the results of the k-means cluster analysis by which stress level groupings based on cortisol data were made.

\begin{tabular}{|c|c|c|c|c|c|}
\hline & \multicolumn{3}{|c|}{ Cluster center } & \multicolumn{2}{c|}{ ANOVA } \\
\cline { 2 - 6 } & $\begin{array}{c}\text { Stress } \\
(\mathbf{N}=\mathbf{8})\end{array}$ & $\begin{array}{c}\text { Non-Stress } \\
\mathbf{( N = 1 0 )}\end{array}$ & $\begin{array}{c}\text { General } \\
\mathbf{( N = 1 5 )}\end{array}$ & $\mathbf{F}$ & $\mathbf{p}$ \\
\hline $\begin{array}{c}\text { Cortisol } \\
(\mathrm{ug} / \mathrm{dL})\end{array}$ & 0.32 & 0.11 & 0.21 & 71.378 & 0.000 \\
\hline
\end{tabular}

Table 4. K-means cluster analysis of cortisol data

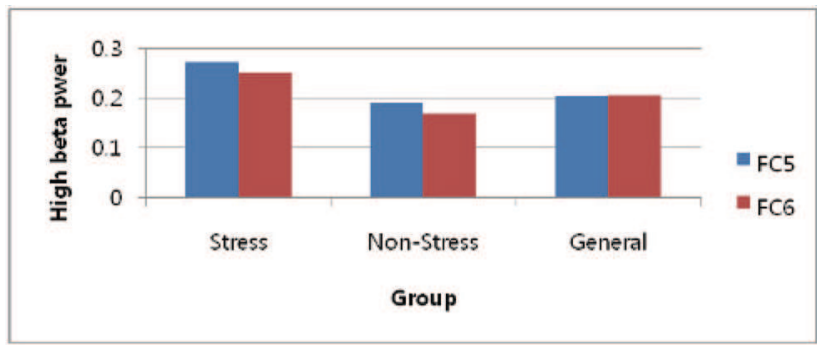

Fig. 4. Relative high beta power in each of the three cortisol-based stress level groups

The mean high beta power at the anterior temporal sites of each cortisol group is shown in Figure 4. There was a significant difference in high beta activity across the groups at both FC5 $(\mathrm{F}=5.556, \mathrm{p}=0.009)$ and FC6 $(\mathrm{F}=3.635, \mathrm{p}=0.039)$ sites. The stress group (with relatively high cortisol levels) had the highest level of beta activity.

The relationship between salivary cortisol level and relative high beta power at each of the four EEG sites in the eyes-closed condition is summarized in Table 4. In this condition, there was a significant positive correlation between the cortisol level and relative high beta power at 
both the anterior temporal sites, and a tendency toward a similar relationship at one of the occipital sites (O2). Significant relationships were not found in any of the other conditions.

\section{Discussion}

There are three major results to report from the present study. The first of these is a significant correlation between HRV and salivary cortisol (but not between HRV and SRI scores). Second, significant correlations exist between relative high beta EEG power at anterior temporal sites and each of HRV and salivary cortisol during an eyes-closed resting condition. The third finding is a difference in the relative high beta power across stress level groups determined on the basis of SDNN and cortisol data. In both instances, the stress group participants had the highest level of beta activity.

Chronic stress leads to increase in the variability of central-autonomic responses and decrease in physiological adaptability and immunity (Fuchs \& Fluegee 1995; Fuchs, Uno \& Fluegge 1995; Cohen et al., 2000; Hughes \& Stoney 2000). There have been many studies using biosignals to quantify the stress associated with mental tasks or work load in healthy subjects (Jeon et al., 2002). These studies have established that biomarker profiles can distinguish between people experiencing chronic stress and those who are not, with sufferers of chronic stress typically having lower HRV and higher cortisol levels. The findings of the present study are thus consistent with those of previous research.

Although many researchers have reported EEG abnormalities as being associated with stress and negative emotions, the extent to which stress can be reliably evaluated from the EEG has been unclear. Recent EEG research on emotion has focused on relationships between dorsolateral prefrontal asymmetry and a dispositional tendency toward positive or negative affects (Davidson 2004). However, some researchers have suggested a need to pay more attention to frontopolar regions of the prefrontal cortex (Papousek \& Schulter 2002). Thompson has indicated that the EEG of someone under stress displays decreases in both alpha (11-12 Hz) and sensorimotor rhythm (SMR, 12-15 Hz) activity, and increases in EEG amplitude in the 19-22 $\mathrm{Hz}$ and high beta $(23-35 \mathrm{~Hz})$ ranges at both $\mathrm{Cz}$ and $\mathrm{FCz}$ sites (Michael \& Lynda 2007). Emotional intensity, particularly relating to anxiety, correlates with 19-22 $\mathrm{Hz}$ band activity, while activity within the $23-36 \mathrm{~Hz}$ band reflects an active brain state. Accortt has reported a relationship between premenstrual distress and frontal EEG alpha, an effect especially pronounced at the anterior temporal sites (Accortt \& Allen 2006). It has also been found that beta rhythms are predominant under resting conditions in bilateral superior temporal and somato-motor regions of the cortex (Mantlnl et al., 2007), both of which are implicated in emotional processes (Hagemann et al., 1998; Davidson et al., 1990).

In the present study, we found a correlation between HRV and high beta activity at anterior temporal sites (FC5, FC6) during the eyes-closed condition. We also found a correlation between salivary cortisol and high beta activity in this condition. These results show that participants with relatively low HRV had relatively high levels of beta activity in premotor regions of the cortex. Participants with a higher level of salivary cortisol also had a higher level of beta activity. These results suggest that there are close relationships among EEG, ECG, and salivary cortisol indicative of chronic stress. Chronic stress was particularly associated with high levels of relative beta power at anterior temporal sites.

We assigned participants to stress level groups on the basis of SDNN and salivary cortisol data. Greater stress was associated with lower HRV (i.e., lower SDNN values) and a higher level of cortisol. The group with the highest stress level showed the highest level of beta activity during the eyes-closed condition. However, there were no significant correlations 
among EEG, ECG, and salivary cortisol data during any of the other conditions: eyes-open, pleasant images, and unpleasant images. These correlations need to be analyzed because of the difference in individual responses to stimuli. Participants experiencing chronic stress showed less HRV than those who were not. Range of variance of HRV features according to stimuli was little.

Finally, the present study demonstrated that there are consistent relationships among EEG, ECG, and salivary cortisol data associated with chronic stress. In addition to confirming the results of previous studies, our results suggest that chronic stress may be reliably assessed by relative high beta EEG power at anterior temporal sites. Indeed, this variable could even be seen as a diathesis for the dysphoria associated with chronic stress.

\section{References}

Accortt, Eynav Elgoavish and Allen, John J.B. 2006. Frontal EEG asymmetry and premenstrual dysphoric symptomatology. Journal of Abnormal Psychology. 115(1), 179-184.

Bao, A.M., Meynen, G., Swaab, D.F., 2008. The stress system in depression and neurodegeneration: focus on the human hypothalamus. Brain Res. Rev. 57, 531-553.

Barlow, J.H., Turner, A.P., and Wright, C.C. Br J Rheumatol, Comparison of clinical and self-reported diagnoses for participants on a community-based arthritis selfmanagement programme , Vol. 37 , pp.985-987, 1998

Belkic, K., Landsbergis, P., Schnall, P. and Baker D., Is job strain a major source of cardiovascular disease risk?, Scandinavian Journal of Work Environment and Health, 30(2), 85-128, 2004.

Bernardi, L., Wdowczyk-Szulc, J., Valenti, C., Castoldi, S., Passino, C., Spadacini, G., and Sleight, P. 2000. Effects of controlled breathing, mental activity, and mental stress with or without verbalization on heart rate variability. Journal of the American College of Cardiology. 35(6), 1462-1469.

Bierhaus, A., Wolf, J., Addrassy, M., Rohleder, N., Humpert, P.M., Petrov, D. et al., "A mechanism converting psychosocial stress into mononuclear cell activation", Proc. Natl. Acad. Sci. USA., vol. 100, no. 4, pp. 1920-1925, 2003.

Bigert, C., Bluhm, G., and Theorell, T. 2005. Saliva cortisol - a new approach in noise research to study stress effects. International Journal of Hygiene and Environmental Health. 208, 227-230.

Cohen, H., Benjamin, J., Geva, A.B., Matar, M.A., Kaplan, Z., and Kotler, M. 2000. Autonomic dysregulation in panic disorder and in post-traumatic stress disorder: application of power spectrum analysis of heart rate variability at rest and in response to recollection of trauma or panic attacks. Psychiatry Research. 96, 1-13

Cohen, S., Kessler, R. and Gordon L. 1997. Measuring stress - A Guide for Health and Social Scientists, Oxford University Press.

Coan, J.A. and Allen, J.J.B., "Frontal EEG asymmetry as a moderator and mediator of emotion", Biol. Psychol., vol. 67, no. 12, pp. 7-49, 2004.

Cohen, S. Tyrrell, D.A. and Smith, A.P. "Negative life events, perceived stress, negative affect, and susceptibility to the common cold", J. Pers. Soc. Psychol., vol. 64, no. 1, pp. 131-140, 1993.

Cooper, C., Stress in the workplace, British Journal of Hospital Medicine, 55, 559-563, 1996.

Davidson, R.J., 2004. What does the prefrontal cortex "do" in affect: perspectives on frontal EEG asymmetry research. Biological Psychology. 67, 219-233.

Davidson, R.J. 1993. Cerebral asymmetry and emotion: Methodological conundrums. Cognition and Emotion, 7, 115-138 
Davidson, R.J., Ekamn, P., Saron, C.D., Senalis, J.A., and Friesen, W.V. 1990. Approachwithdrawal and cerebral asymmetry: emotional expression and brain physiology I. Journal of Personality and Social Psychology. 58, 330-341.

Davidson, R.J., Jackson, D.C., and Kalin, N.H., "Emotion, plasticity, context and regulation: Perspectives from affective neuroscience", Psychol. Bull., vol. 126, no. 6, pp. 890-906, 2000.

Davidson, R.J., Schwartz, G.E., Saron, C., Bennett, J. and Goldman, D.J., “Frontal versus parietal EEG asymmetry during positive and negative affect", Psychophysiology., vol. 16, pp. 202-203, 1979.

Davidson, R.J., "Affective neuroscience and psychophysiology: Toward a synthesis", Psychophysiology, vol. 40, no. 5, pp. 655-665, 2003.

Davidson, R.J., "Anterior cerebral asymmetry and the nature of emotion”, Brain Cogn., vol. 20, no. 1, pp. 125-151, 1992.

Decker, D., Schondorf, M. Bidlingmaier, F., Himer, A., and von Ruecker, A.A. 1996. Surgical stress induces a shift in the type-1/type-2 T-helper cell balance, suggesting downregulation of cell-mediated and up-regulation of antibody-mediated immunity commensurate to the trauma. Surgery. 119, 316-325.

Driskell, K. and Salas, E., Stress and human performance, Lawrence Erlbaum, 1996.

Epel, E.S., Blackburn, E.H., Lin, J., Dhabar, F., Adler, N., Morrow, J. and Cawthon, R. "Accelerated telomere shortening in response to life stress", Proc. Natl. Acad. Sci. USA., vol. 101, no. 49, pp. 17312-17315, 2004.

Fuchs, E. and Fluegee, G. 1995. Modulation of binding sites for corticotrophin-releasing hormone by chronic psychosocial stress. Psychoneuroendocrinology. 20, 33-51.

Fuchs, E., Uno, H., and Fluegge, G. 1995. Chronic psychosocial stress induces morphological alterations in hippocampal pyramidal neurons of the tree shrew. Brain Research. 673, 275-282.

Gevins, A., Smith, M.E., Leong, H., McEvoy, L., Whitfield, S., Du, R. and Rush, G. 1998. Monitoring working memory load during computer-based tasks with EEG pattern recognition Methods. Human Factors. 40(1), 79-91.

Hayano J., Skakibara Y., Yamada A. et al. Accuracy of assessment of cardiac vagal tone by heart rate variability in normal subjects. Am J Cardiol 1991; 67; 199-204.

Hagemann, D., Naumann, E., Becker, G., Maire, S., and Bartussek, D. 1998. Frontal brain asymmetry and affective style: a conceptual replication. Psychophysiology. 35, 372-388.

Hilz, M.J., Dütsch, M., Perrine, K., Nelson, P.K., Rauhut, U., and Devinsky, O. 2001. Hemispheric influence on autonomic modulation and baroreflex sensitivity. Annals of Neurology. 49, 575-584.

Horsten M, Ericson M, Perski A, Wamala SP, Schenck-Gustaffson K, Orth-Gomér K ,1999, Psychosocial factors and heart rate variability in healthy women. Psychosom Med 61:49-57.

Hughes, J.W. and Stoney, C.M., 2000, Depressed mood is related to high-frequency heart rate variability during stressors. Psychosomatic Medicine. 62, 796-803.

Jeon, Y.J., Lee, N.B., Im, J. J., Kwan D.H., and Shin, G.S. 2002. A study for the extraction of stress index using physiological signal variations. Journal of the Ergonomics Society of Korea. 21(4), 1-13.

Johannes, K., Richard, W., and Ulrike, J. "The processing of word stress: EEG studies on taskrelated components", in 16th International Congress of Phonetic Sciences, 2007, pp. 709-712.

Johnson, E.O., Kamilaris, T.C., Chrousos, G.P., Gold, P.W., 1992. Mechanisms of stress: a dynamic overview of hormonal and behavioral homeostasis. Neurosci. Biobehav. Rev. 16, 115-130. 
Kim, D., Seo, Y., and Salahuddin L. 2008. Decreased Long Term Variations of Heart Rate Variability in Subjects with Higher Self Reporting Stress Scores. In Proceedings of the international conference on Pervasive Computing Technologies for Healthcare(The Tampere, The Finland Jan.30-Feb.1, 289-292, 2008).

Kim, J.Y, Park, M.Y. and Park, C.S. "Psychophysiological responses reflecting driver's emotional reaction to interior noise during simulated driving", Human Factors and Ergonomics Society Annual Meeting Proceedings, Psychophysiology in Ergonomics, vol. 3, pp. 196-199, 2000.

Koh, K., Park, J., Kim, C., and Cho, S. 2001. Development of the Stress Response Inventory and its application in clinical practive. Psychosomatic Medicine. 63, 668-678.

Kohlish, O. and Schaefer, F. 1996. Physiological changes during computer task: responses to mental load or to motor demands. Ergonomics. 39(2), 213-224.

Lawrence, D.A., and Kim, D. 2000. Central/Peripheral nervous system and immune responses. Toxicology. 142, 189-201.

Lang, P.J., Bradley, M.M., and Cuthbert, B.N. 1995. NIMH Center for the Study of Emotion and Attention, international Affective Picture System (IAPS). Technical Manual and Affective Ratings.

Lewis, R.S., Weekes, N.Y. and Wang, H.W. "The effect of a naturalistic stressor on frontal EEG asymmetry, stress, and health", Biol. Psychol., vol. 75, no. 3, pp. 239-247, 2007.

Mantlnl, D., Perruccl, M.G., DelGratta, C., Romanl, G.L., and Corbetta, M. 2007. Electrophysiological signatures of resting state networks in the human brain. PANS. 104(32), 13170-13175.

Manning, M., Jackson, C. and Fusilier, M., Occupational stress, social support, and the costs of health care, Academy of Management Journal, 39, 738-750, 1996.

Malliani A., Pagani M., Lombardi F, Cerutti S. Cardiovascular neural regulation explored in the frequency domain. Circulation 1991; 84: 1482-92.

Margaret M. Bradley et, al. 1994. Measuring Emotion: The Self-Assessment Manikin and Semantic Differential. J. Behavther \& Exp, Psychiat. 25(1), 49-59.

Matsunami, K., Homma, S., Han, X.Y. and Jiang, Y.F., "Generator sources of EEG Large Waves Elicited by mental stress of memory recall or mental calculation", Jpn J Physiol., vol. 51, no. 5, pp. 621-624, 2001.

McEwen, B.S. The End of Stress as We Know It, Joseph Henry Press and Dana Press, 2002, pp. 17-54.

Michael Thompson and Lynda Thompson, 2007. Neurofeedback for Stress Management. Principles and Practice of Stress Management, Paul M. Lehrer, Robert L. Woolfolk, Wesley E. Sime Ed. Guilford Press, 249-287.

Ministry of Labor in South Korea, Present state of industrial disasters, 2008.

Myrtek M, Weber D, Brügner G, Müller W ,1996, Occupational stress and strain of female students: results of physiological, behavioural, and psychological monitoring. Biol Psychol 42:379-391.

NIOSH, Stress at work, NIOSH publication Number 99-101, 1999.

Noback C.R., Demarest R.J. ,1986, The Nervous System, Introduction and Review, McCraw Hill.

Park, S. and Kim, D. 2007. Relationship between Physiological Response and Salivary Cortisol Level to Life Stress. Journal of the Ergonomics Society of Korea. 26(1), 11-18.

Papousek, I. and Schulter, G. 2002. Covariations of EEG asymmetries and emotional states indicate that activity at frontpolar locations is particularly affected by state factors. Psychophysiology. 39(3), 350-60.

Patrick W. Corrigan, Kim T. Mueser, Gary R. Bond, Robert E. Drake, Phyllis Solomon, Principles and Practice of Psychiatric Rehabilitation, Guilford Press. 2008. 
Paul G. Swingle., 2008, Biofeedback for the Brain: how neurotherapy effectively treats depression, ADHD, autism, and more, Rutgers university press.

Pomeranz B., Bacaulay R.J.B., Caudill M.A. et al. Assessment of autonomic function in humans by heart rate spectral analysis. Am J Physiol 1985; 248: H151-3

Ritvanen, T., Louhevaara, V., Helin, P., Vaisanen, S., and Hanninen, O. 2005. Responses of the autonomic nervous system during periods of perceived high and low work stress in younger and older female teachers. Applied Ergonomics 37, 311-318.

Rober L.Woolfolk, Wesley E. Sime, Paul M. Lehrer, Principles and practice of stress management, Gillford Press. 2007. Neurofeedback for stress management, Michael Thompson \& Lynda Thompson p249-287

Schulter, G. and Papousek, I. 1998. Bilateral electrodermal activity: relationships to state and trait characteristics of hemisphere asymmetry. International Journal of Psychophysiology. 31, 1-12.

Segerstrom, S.C. and G.E. Miller, G.E. "Psychological stress and the human immune system: A meta-analytic study of 30 years of inquiry", Psychol. Bull., vol. 130, no. 4, pp. 601630, 2004.

Seo, S.H., Gil, Y.J., and Lee. J.T. 2008a. The effect of auditory stressor, with respect to affective style, on frontal EEG asymmetry and ERP analysis. In proceedings of the international conference on networked computing and advances in information management (Kyungju, The South Korea, 662-667, 2008)

Seo, S.H., Gil, Y.J., and Lee. J.T. 2008b. The relation between affective style of stressor on EEG asymmetry and stress scale during multimodal task. In proceedings of the international conference on convergence and hybrid information technology (Busan, The South Korea, 461-466, 2008)

Sloan RP, Shapiro PA, Bagiella E, Boni SM, Paik M, Bigger JT, Steinman RC, Gorman JM, 1994, Effect of mental stress throughout the day on cardiac autonomic control. Biol Psychol 37:89-99.

Theorell T, Ahlberg-Hulten G, Jodko M, Sigala F, de la Torre B ,1993, Influence of job strain and emotion on blood pressure in female hospital personnel during work hours. Scand J Work Environ Health 19: 313-318

Tucker, D.M. "Lateral brain function, emotion, and conceptualization", Psychological Bulletin, vol. 89, no. 1, pp. 19-46, 1981.

Turner Charles F, Ku Leighton, Rogers SusanM, Lindberg Laura D, Pleck Joseph H, Sonnenstein Freya L. Adolescent Sexual Behavior, Drug Use, and Violence: Increased Reporting with Computer Survey Technology. Science. 1998;280:867-73.

Van der Kar, L.D. and Blair, M.L. 1999. Forebrain pathways mediating stress induced hormone secretion. Frontiers in Neuroendocrinology. 20, 41-48.

Wittling, W. 1995. Brain asymmetry in the control of autonomic-physiological activity. In Brain Asymmetry, R.J. Davidson \& K. Hugdahls, Ed. Cambridge: MIT press. 305-358.

Yoon, S.J., Kim, T.S., and Chae, J.H. 2005. Understanding Stress by Neuroscience. Journal Korean Acad. Fam. Med. 26, 439-450.

Zhong, X., Hilton, H.J., Gates, G.J., Jelic, S. Stern, Y, Bartels, M.N., DeMeersman, R.E., and Basner, R.C. 2005. Incresed sympathetic and decreased parasympathetic cardiovascular modulation in normal humans with acute sleep deprivation. J Appl Physiol. 98(6), 2024-2032. 


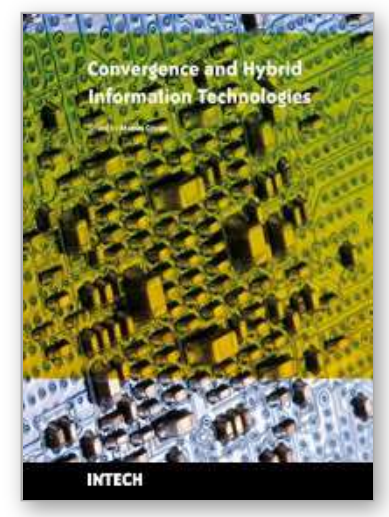

\section{Convergence and Hybrid Information Technologies \\ Edited by Marius Crisan}

ISBN 978-953-307-068-1

Hard cover, 426 pages

Publisher InTech

Published online 01, March, 2010

Published in print edition March, 2010

Starting a journey on the new path of converging information technologies is the aim of the present book. Extended on 27 chapters, the book provides the reader with some leading-edge research results regarding algorithms and information models, software frameworks, multimedia, information security, communication networks, and applications. Information technologies are only at the dawn of a massive transformation and adaptation to the complex demands of the new upcoming information society. It is not possible to achieve a thorough view of the field in one book. Nonetheless, the editor hopes that the book can at least offer the first step into the convergence domain of information technologies, and the reader will find it instructive and stimulating.

\section{How to reference}

In order to correctly reference this scholarly work, feel free to copy and paste the following:

Ssang-Hee Seo and Jung-Tae Lee (2010). Stress and EEG, Convergence and Hybrid Information Technologies, Marius Crisan (Ed.), ISBN: 978-953-307-068-1, InTech, Available from:

http://www.intechopen.com/books/convergence-and-hybrid-information-technologies/stress-and-eeg

\section{INTECH}

open science | open minds

\section{InTech Europe}

University Campus STeP Ri Slavka Krautzeka 83/A 51000 Rijeka, Croatia Phone: +385 (51) 770447 Fax: +385 (51) 686166 www.intechopen.com

\section{InTech China}

Unit 405, Office Block, Hotel Equatorial Shanghai No.65, Yan An Road (West), Shanghai, 200040, China 中国上海市延安西路65号上海国际贵都大饭店办公楼405单元 Phone: +86-21-62489820

Fax: $+86-21-62489821$ 
(C) 2010 The Author(s). Licensee IntechOpen. This chapter is distributed under the terms of the Creative Commons Attribution-NonCommercialShareAlike-3.0 License, which permits use, distribution and reproduction for non-commercial purposes, provided the original is properly cited and derivative works building on this content are distributed under the same license. 